\title{
Synthesis and characterization of graphene oxide based inverse spinel nickel ferrites nanocomposites for the removal of $\mathrm{As}(\mathrm{V})$
}

\author{
(Graphene oxide based nanocomposites for the adsorption removal of $A s(V)$ ) \\ Yu-Lim Choi ${ }^{\mathrm{a}}$, Lakshmi Prasanna Lingmadinne ${ }^{\mathrm{a}}$, Jae-Kyu Yang ${ }^{\mathrm{b}}$, Yoon-Young Chang ${ }^{\mathrm{a}}$, Janardhan \\ Reddy Koduru ${ }^{c_{*}}$
}

\begin{abstract}
In order to develop water treatment performance, graphene oxide based inverse spinel nickel ferrites (GONF) and reduced graphene oxide based inverse spinel nickel ferrites (rGONF) nanocomposites were prepared using graphene oxide (GO) and inverse spinel nickel ferrite $\left(\mathrm{NiFe}_{2} \mathrm{O}_{4}\right)$ by thermal precipitation method. The interface interactions of GO and $\mathrm{NiFe}_{2} \mathrm{O}_{4}$ were studied. The $\mathrm{X}$-ray diffraction spectrometer (XRD), and Fourier-transform infrared spectroscopy (FT-IR) and BET studies showed that the formation GONF and rGONF. Scanning electron microscopy (SEM) studies observed porous surface morphology of GONF and rGONF. The magnetic studies revealed that the ferromagnetic property of GONF and rGONF, but the later one shows less Ferro magnetic intensity than GONF. It was well performed for the adsorption removal $\mathrm{As}(\mathrm{V})$ and subsequently easy magnetic separation from water. The sorption studies revealed that the sorption was rate-limiting pseudo -second-order kinetics with mono layer chimisorptions on homogeneous surface of GONF and rGONF. The sorption capacity of GONF enhanced by the reducing of GO. The sorption capacity of rGONF (106.38 $\mathrm{mg} / \mathrm{g})$ was higher than GONF (81.30) for $\operatorname{As}(\mathrm{V})$. It was decreased with increasing temperature from 293 to $323 \pm 2 \mathrm{~K}$. The influence of sorption with solution $\mathrm{pH}$ and spectral characterisation of loaded GONF-As(V) or rGONF-As(V) were further confirmed that the sorption occurred through an inner sphere surface complexation by chemical interactions
\end{abstract}

Keywords - graphene oxide, graphene oxide based nanocomposites, nickelferrite, $\operatorname{arsenic}(\mathrm{V})$

a (Yu-Lim Choi, Lakshmi Prasanna Lingmadinne, Yoon-Young Chang): Department of Environmental Engineering, Kwangwoon University, Seoul, 139-701, Republic of Korea

b(Jae-Kyu Yang):

Division of General Education, Kwangwoon University, Seoul, 139-701, Republic of Korea

'(Janardhan Reddy Koduru):

Graduate School of Environmental Studies, Kwangwoon University, Seoul, 139-701, Republic of Korea

* Corresponding author.

\section{Introduction}

Graphene oxide (GO), have large specific surface areas and good biocompatibility, is widely used in various applications. Most of the graphene oxides usually have several functional groups such as hydroxyl and carboxyl, showing extended adsorption property for heavy metal ions and organic pollutants [1]. Currently magnetic graphene oxide or graphene based nanomaterials [2] have been fabricated and used for drug delivery [3], energy storage [4], and water treatment $[5,6]$. In the recent years, magnetic materials have been widely used as an adsorbent for treatment of toxic contaminates [7-9]. Moreover, magnetite metal oxides or various ferrites are frequently used in hydrometallurgical extraction process for recovery of precious metals [10] and heavy metals [11,12], and regulating digestion of high silica bauxite [13]. Among the available magnetic sorbents, inorganic spinel ferrites and their composite materials were widely used in water treatment due to its unique advantages of magnetic and chemical stability $[8,14-16]$. Synthesized magnetic inverse spinel nickel ferrite nanocomposite materials composed with GO (GONF) or reduced GO (rGONF) by hydro thermal method, were used in the present study for the treatment of $\operatorname{As}(\mathrm{V})$ from water.

\section{Methods and Materials}

\section{A. Preparation porous GONF and rGONF}

As shown in the Scheme 1, prepared GONF and rGONF from GO and nickel ferrite by thermal co-precipitation method. The GO was prepared from Graphite flakes oxidation using Hummer's method and subsequently utrasonication. Further, the prepared GO was reduced using $\mathrm{N}_{2} \mathrm{H}_{4}$ for preparation reduced ( $\mathrm{rGO}$ ). The prepared $\mathrm{GO}$ and rGO were used for the preparation of GONF and rGONF.

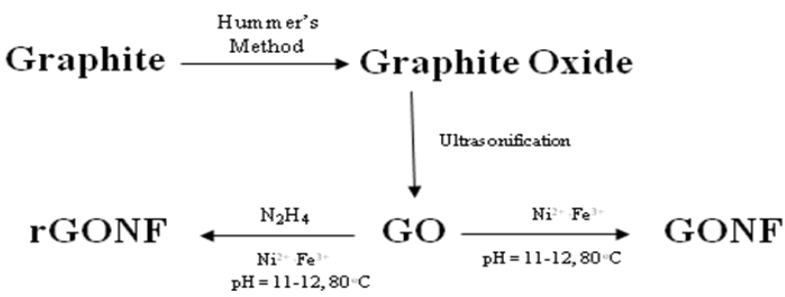

Scheme 1. Schematic representation for the preparation GONF and rGONF 
Proc. of the Third Intl. Conf. on Advances in Bio-Informatics and Environmental Engineering - ICABEE 2015

Copyright (C) Institute of Research Engineers and Doctors, USA .All rights reserved.

ISBN: 978-1-63248-078-1 doi: 10.15224/ 978-1-63248-078-1-05

\section{B. Batch sorption experiments}

The stock solution $(1000 \mathrm{mg} / \mathrm{L})$ of metal ion, As(V), was prepared from $\mathrm{Na}_{3} \mathrm{AsO}_{4}$. Typical batch sorption experiment were carried out with $50 \mathrm{~mL}$ of $7 \mathrm{mg} / \mathrm{L}$ aqueous solution of $\mathrm{As}(\mathrm{V})$ initial concentration at $\mathrm{pH} 2.0$ in a falcon tube at room temperature. To this added each $0.3 \mathrm{~g} / \mathrm{L}$ of GONF and rGONF. Then, mixture was shaken for pre-determined equilibrium time intervals (150 $\mathrm{min})$, and the samples were filtered out through a $0.45 \mu \mathrm{m}$ membrane syringe filter for measuring the metal ion concentration using Optima 2100 DV inductive coupled plasmaoptical emission spectroscopy (ICP-OES) (Perkin-Elmer, USA). The amount of $\mathrm{As}(\mathrm{V})$ adsorbed onto GONF and rGONF were calculated from the mass balance between the initial $\left(C_{o}\right)$ and equilibrium $\left(C_{e}\right)$ concentrations $(\mathrm{mg} / \mathrm{L})$ of metal ions. The metal uptake capacity $\left(q_{e}, \mathrm{mg} / \mathrm{g}\right)$ of nanocomposite materials was calculated by the following equation:

$$
q_{e}=\frac{\left(c_{0}-c_{e}\right) V}{m}
$$

where $V$ is the volume of $\mathrm{As}(\mathrm{V})$ solution and $m(\mathrm{~g})$ is the weight of GONF or rGONF. All $\mathrm{pH}$ measurement was carried out by $340 \mathrm{i} \mathrm{pH}$ meter (WTW, Germany). The sorption experiment was also performed at different $\mathrm{pH}$ values by adjusting $\mathrm{pH}$ with 0.1 moles/ $\mathrm{L} \mathrm{HCl}$ and $\mathrm{NaOH}$ solutions. Desorption studies were conducted using $\mathrm{pH} 1.0$ aqueous $\mathrm{HNO}_{3}$ acid solution. All the investigations were carried out in triplicate to avoid discrepancies in experimental results and the values reported are mean \pm standard deviation (SD). Origin 8.0@ was used to fit the kinetics and equilibrium models using linear regression analysis. Metal solution controls were also utilized to maintain quality control.

\section{Results and Discussions}

The X-ray diffraction results (XRD) (Fig.1) observed that the crystalline property of GO decreased as meso-pours carbonaceous material in the modified GONF or the reduced GONF increased. The strong peak at $2 \theta=11.3^{\circ}$ confirmed the formation GO and was shifted to lower range $(2 \theta=8.9$ and $5.6^{\circ}$ ) at the GONF and rGONF [17]. The peaks at $2 \theta=$ $26.6,35.65$ and $44.5^{\circ}$ values indicated the presence of spinel nickel ferrite in the GONF and rGONF [18]. However, the nickel ferrite diffractions peaks $(2 \theta: 26.35,35.60$ and $43.20^{\circ}$ ) values were shifted to slightly lower range in the rGONF than in the GONF. It may be due to the decreased size and increased porous surface area of GONF by reduction. The decreased size of GONF by the reduction with hydrazine hydride was also clearly observed from the X-ray diffraction studies of GONF and rGONF, i.e. from $41.0 \mathrm{~nm}(\mathrm{GONF})$ to $32.12 \mathrm{~nm}$ (rGONF). It was calculated from well-known Scherer formula: $D=0.94 \lambda / \beta \cos \theta$, where $D$ is the crystallite size (nm), $\beta$ is the full width of the diffraction line at half of the maximum intensity measured in radians, $\lambda$ is the $\mathrm{X}$-ray wavelength of $\mathrm{Cu} \mathrm{K} \alpha=0.154 \mathrm{~nm}$, and $\theta$ is the Bragg angle. Finally the XRD results were confirmed that the formation of GO-based cubic spinel nickel ferrite nano composites, GONF and rGONF.

Further FT-IR results (Fig.2) suggest the presence of epoxy and carbonyl functional groups along with carboxylic groups which confirming the formation of GO. FT-IR spectrum of GONF or rGONF indicates that the wavelengths of such functional groups present in GO were shifted to lower wavelengths regions upon magnetization of GO or the reduction of GONF. It is a common phenomenon for the formation of new product from bare compound by reduction

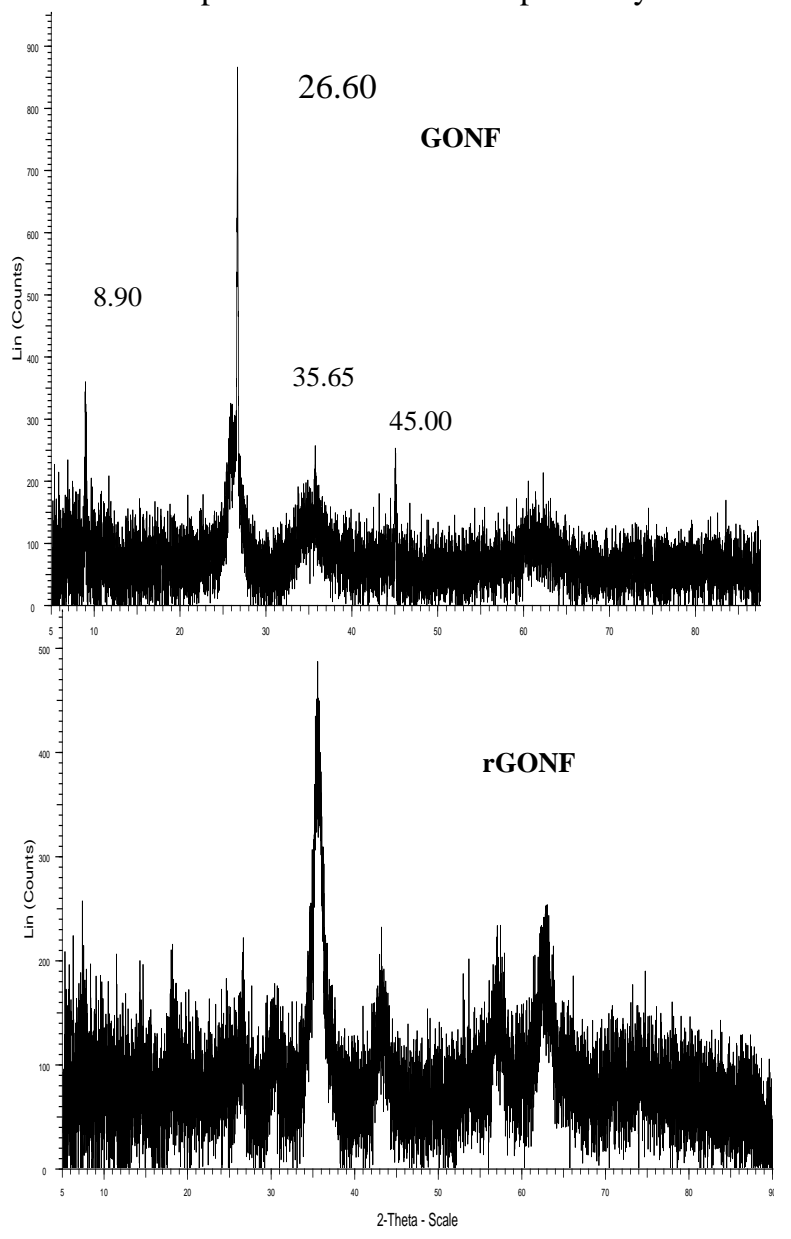

Fig.1. X-ray diffraction studies of prepared GONF and rGONF nanocomposites

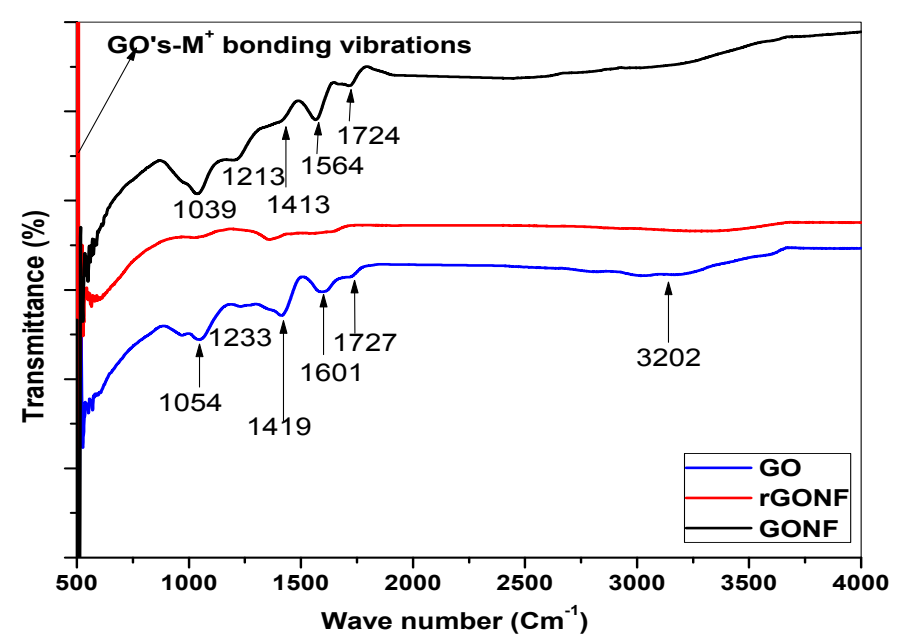

Fig.2. FT-IR spectrum of prepared GO, GONF and rGONF nanocomposites.

or magnetization. The shifting of absorption peaks is associated with the formation of GONF and rGONF from 
Proc. of the Third Intl. Conf. on Advances in Bio-Informatics and Environmental Engineering - ICABEE 2015

Copyright (C) Institute of Research Engineers and Doctors, USA .All rights reserved.

ISBN: 978-1-63248-078-1 doi: 10.15224/ 978-1-63248-078-1-05

the GO. The sharp peaks at $550-500 \mathrm{~cm}^{-1}$ indicates the tetrahedral and octahedral $\mathrm{Fe}-\mathrm{O}$ or $\mathrm{Ni}-\mathrm{O}$ bonds.

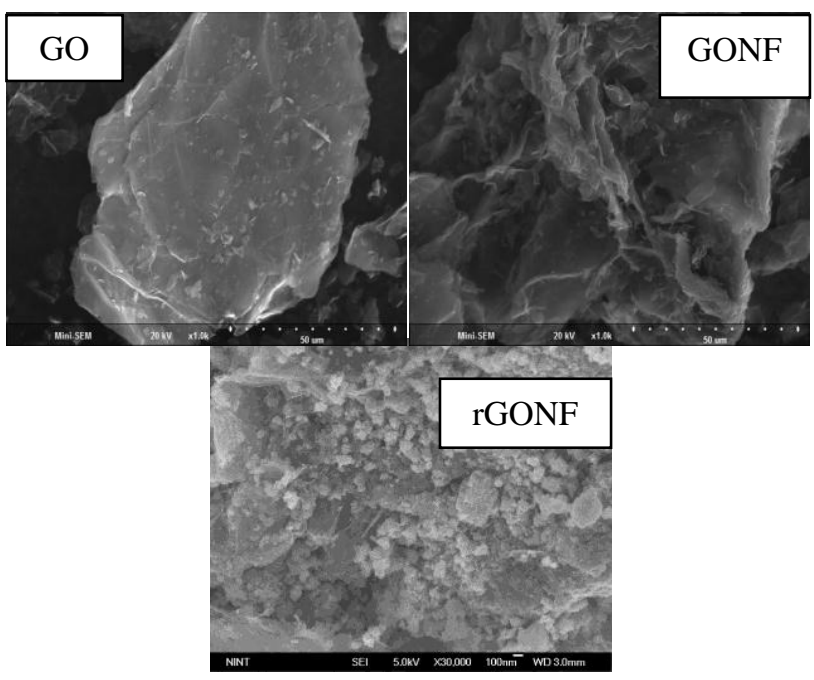

Fig.3. Scanning Electron Microscopy (SEM) images of bare GO, GONF, and rGONF nanocomposites for recognition of surface morphology.

The BET surface area of GO increases from 2.59 to 167.26 $\mathrm{m}^{2} / \mathrm{g}$ as particle size decreases from $1000 \mathrm{~nm}$ to $34.46 \mathrm{~nm}$ from the conversion of GO to rGONF. It may be due to the formation of end product, rGONF by the intercalation of cubic spinel $\mathrm{NiFe}_{2} \mathrm{O}_{4}$ with GO. The reduction or modifications of GO with nickel ferrite increases its surface area in a large size and is favorable for enhances its adsorption capacity. The size of prepared GONF (44.12 nm) and rGONF (34.46). The significant changes in surface texture of GO upon intercalation of nickel ferrite lead to increases porosity with increasing surface area of GONF and rGONF. The resultant average pore volume and pore diameter of GONF and rGONF indicates the nanocrystalline meso-porous composite particles. The magnetic hysteresis curves $(M-H)$ of nano magnetic spinel GONF and rGONF composite were recorded at $300 \mathrm{~K}$ indicated that the paramagnetic property of GONF and rGONF was confirmed from magnetic susceptibility $(\chi)$ determined from the slope of $M-H$ curve. Magnetic susceptibility $(\chi)$ are $+1.8 \times 10^{-3}$ $\mathrm{emu} / \mathrm{cm}^{3} \cdot$ Oe for the GONF and $+1.45 \times 10^{-4} \mathrm{emu} / \mathrm{cm}^{3} \cdot$ Oe for the rGONF. The SEM images of GO, GONF and rGONF were shown in Fig. 3. The obtained surface images clearly indicate increase of porosity as decreasing particle size along with significant difference in surface morphology due to the formation of GONF and rGONF from GO. The obtained porous surface morphology is favorable for surface interface studies such as adsorption. Hence, the prepared GONF and rGONF can be used as adsorbents.

In order to check the water treatment performance, $\mathrm{As}(\mathrm{V})$ batch adsorption studies were performed using the prepared GONF and rGONF at $\mathrm{pH}$ 2.0. The effect of contact time for adsorption of $\mathrm{As}(\mathrm{V})$ onto rGONF and GONF was investigated to evaluate the equilibrium point. Fig. 4 showed the adsorption of $\mathrm{As}(\mathrm{V})$ at different time intervals with $7 \mathrm{mg} / \mathrm{L}$ initial metal ion concentration at $\mathrm{pH}$ 2.0 and 298 K. From the results, it can be clearly observed that the $\mathrm{As}(\mathrm{V})$ adsorption was very rapid during the first 20 min, and then slowly increased and reached an equilibrium at $150 \mathrm{~min}$. The initial very fast adsorption of $\mathrm{As}(\mathrm{V})$ can be explained by that GONF and rGONF have more freely available reactive sites with high surface area and relatively large pore sizes.

In order to check sorption mechasim of $\mathrm{As}(\mathrm{V})$ on to GONF and rGONF Pseduo-first and second-order kinetics models applied to the above kinetic data and the results confirmed that the sorption of $\mathrm{As}(\mathrm{V})$ was rate-limiting pseudo-second-kinetics. The Langmuir and Freundlich isotherm models were applied to the adsorption data and the results shown in the Tabe 1 . The obtained results observed that the sorption data was well tune with Langmuir isotherm indicated that the $\mathrm{As}(\mathrm{V})$ sorption was monolayer on homogeneous surface of GONF and rGONF at room temperature. The sorption capacity of rGONF $(106.38 \mathrm{mg} / \mathrm{g})$ was higher than GONF (81.30 $\mathrm{mg} / \mathrm{g})$ for As(V). As increasing the temperature from 293 to $323 \pm 2 \mathrm{~K}$, the sorption was decreased. The influence of sorption with solution $\mathrm{pH}$ and spectral characterization of loaded GONF$\mathrm{As}(\mathrm{V})$ or rGONF-As(V) were further confirmed that the sorption occurred through an inner sphere surface complexation by chemical interactions.

\section{Conclusions}

The prepared GONF and rGONF nanocomposites were confirmed by means of instrumental techniques, XRD, FTIR, SEM and BET results. The size of GONF $(44.12 \mathrm{~nm})$ is decreased by the formation of $\operatorname{rGONF}(34.46 \mathrm{~nm})$. The sorption kinetics was rate-limiting kinetics. The sorption of GONF is 81.38 , where rGONF (106.38 mg/g) is almost three times more than the GONF.

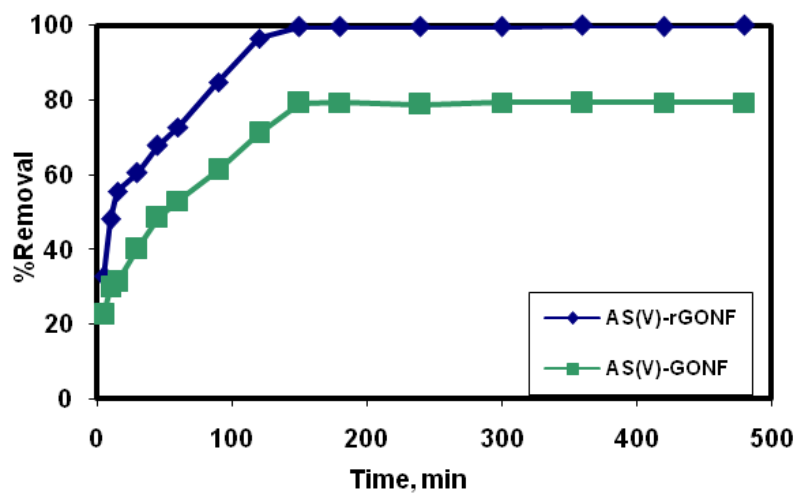

Fig.4. Contact time effect on adsorption of $\mathrm{As}(\mathrm{V})$ on to GONF and rGONF at $\mathrm{pH} 2.0$, and room temperature.

TABLE I. Isotherm parameters of As(V) sorption onto rGONF and GONF

\begin{tabular}{|l|l|l|l|l|l|l|}
\hline \multirow{2}{*}{ Adsorbent } & \multicolumn{3}{|l|}{ Langmuir } & \multicolumn{3}{|l|}{ Freundlich } \\
\cline { 2 - 7 } & $\begin{array}{l}q_{m}, \\
m g / g\end{array}$ & $\begin{array}{l}K_{L} \\
L m g^{-} \\
I\end{array}$ & $R^{2}$ & $\begin{array}{l}K_{F}, \mathrm{mg} \\
\mathrm{g}-{ }_{-}(\mathrm{L} \\
\mathrm{mg-} \\
\left.{ }^{1}\right)^{1 / n}\end{array}$ & $n$ & $R^{2}$ \\
\hline GONF & 81.30 & 0.57 & 0.998 & 25.92 & 1.86 & 0.943 \\
\hline rGONF & 106.38 & 0.27 & 0.999 & 79.72 & 1.804 & 0.956 \\
\hline
\end{tabular}


Proc. of the Third Intl. Conf. on Advances in Bio-Informatics and Environmental Engineering - ICABEE 2015

Copyright (C) Institute of Research Engineers and Doctors, USA .All rights reserved. ISBN: 978-1-63248-078-1 doi: 10.15224/ 978-1-63248-078-1-05

\section{Acknowledgment}

This work was supported by the Korean Ministry of the Environment as part of the "GAIA project (2014000550003)" with additional supported from the "Research Grant-2015" of Kwangwoon University, Seoul, Korea.

\section{References}

[1] J. Li, S. J. Guo, Y. M. Zhai and E. K. Wang, "Nafion-graphene nanocomposite film as enhanced sensing platform for ultrasensitive determination of cadmium," Electrochem. Communications, 2009, vol. 11(5), pp. 1085-88

[2] X. M. Chen, G. H. Wu, Y. Q. Jiang, Y. R. Wang and X. Chen, "Graphene and graphene-based nanomaterials: the promising materials for bright future of electroanalytical chemistry," Analyst, 2011, vol. 136, pp. 4631-4640.

[3] C. Chen, W. Cai, M. Long, B. Zhou, Y. Wu, D. Wu and Y. Feng, "Synthesis of visible-light responsive graphene oxide/TiO2 composites with p/n heterojunction," ACS Nano, 2010, vol. 4(11), pp. 6425-6432.

[4] M. Zhang, D. N. Lei, X. M. Yin, L. B Chen, Q. H. Li, Y. G. Wang and T. H. Wang, "Magnetite/graphene composites: microwave irradiation synthesis and enhanced cycling and rate performances for lithium ion batteries,"J. Material Chem., 2010, vol. 20(26), pp. 5538-5543.

[5] H. Y. Koo, H. J. Lee, H. A. Go, Y. B. Lee, T. S. Bae, J. K. Kim and W. S. Choi, "Graphene-Based Multifunctional Iron Oxide Nanosheets with Tunable Properties. Chemistry- A European J., 2012, vol. 17(4), pp. 1214-1219.

[6] S. Xu, F. Zhang, Q. Kang, S. Liu and Q. Cai, "The effect of magnetic field on the catalytic graphitization of phenolic resin in the presence of Fe-Ni," Carbon, 2009, vol. 47, pp. 3233-3237.

[7] J. R. Koduru, Y. Y. Chang, J. K. Yang and I. S. Kim, "Iron oxide impregnated morus alba L. fruit peel for biosorption of Co(II): Biosorption properties and mechanism," The Scientific World J. 2013, vol. 2013, Article ID 917146, 14 pages, doi:10.1155/2013/917146.

[8] L. P. Lingamdinne, J. R. Koduru, Y. L. Choi, Y. Y. Chang and J. K. Yang, "Studies on removal of $\mathrm{Pb}$ (II) and $\mathrm{Cr}$ (III) using graphene oxide based inverse spinel nickel ferrite nano composite as sorbent," Hydrometallugy, 2015 (Accepted, Inpress).

[9] L. P. Lingamdinne, J. Y. Yang, Y. Y. Chang, J. R. Koduru, "Low-cost magnetized Lonicera japonica flower biomass for the sorption removal of Heavy metals," Hydrometallurgy, 2015: http://dx.doi.org/10.1016/j.hydromet.2015.10.022

[10] R. Ranjbar, M. Naderi, H. Omidvar and Gh. Amoabediny, "Gold recovery from copper anode slime by means of magnetite nanoparticles (MNPs), Hydrometallurgy, 2014, vol.143, pp. 54 59.

[11] M. I. Muravyov, N. V. Fomchenko, A. V. Usoltsev, E. A. Vasilyev and T. F. Kondrat'eva, "Leaching of copper and zinc from copper converter slag flotation tailings using H2SO4 and biologically generated $\mathrm{Fe}_{2}(\mathrm{SO} 4)_{3}$," Hydrometallurgy, 2012, vol. $119-120$, pp. $40-46$

[12] Z. Zhao, W. Shuai, J. Zhang and X. Chen, "Sn(IV) anions adsorption onto ferric hydroxide: A speciation-based model, Hydrometallurgy, 2013, vol. 140, pp. 135-143.

[13] X. Li, S. Gu, Z. Yin, G. Wu and Y. Zhai, "Regulating the digestion of high silica bauxite with calcium ferrite addition. Hydrometallurgy, 2010, vol. 104, pp. 313-316

[14] X. Hou, J. Feng, Y. Ren, Z. Fan and M. Zhang, "Synthesis and adsorption properties of sponge like porous $\mathrm{MnFe}_{2} \mathrm{O}_{4}$," Colloids Surface Physicochemistry Eng. Aspects., 2010, vol.363, pp.1-7.

[15] S. Lv, X. Chen, Y. Ye, S.Yin, J. Cheng and M. Xia "Rice hull/ $\mathrm{MnFe}_{2} \mathrm{O}_{4}$ composite: Preparation, characterization and its rapid microwave-assisted COD removal for organic wastewater," J. Hazard. Mater., 2009, vol. 171, pp. 634-639.

[16] Y. Ren, Q. Dong, J. Feng, J. Ma, Q. Wen and M. Zhang, "Magnetic porous ferro spinel $\mathrm{NiFe}_{2} \mathrm{O}_{4}$ : A novel ozonation catalyst with strong catalytic property for degradation of di-nbutyl phthalate and convenient separation from water," $\mathrm{J}$. Colloid Interface Sci. 2012, vol. 382, pp. 90-96.
[17]Z.J Fan, K. Wang, T. Wei, J. Yan, L. P. Song and B. Shao, “An environmentally friendly and efficient route for the reduction of graphene oxide by aluminum powder," Carbon, 2010, vol. 48(5), pp. 1670-1692.

[18] B. Senthilkumar, R. Kalai Selvan, P. Vinothbabu, I. Perelshtein and A. Gedanken, "Structural, magnetic, electrical and electrochemical properties of $\mathrm{NiFe}_{2} \mathrm{O}_{4}$ synthesized by the molten salt technique. Mater. Chem. and Phys., 2011, vol. 130, pp. 285292.

About Author (s):

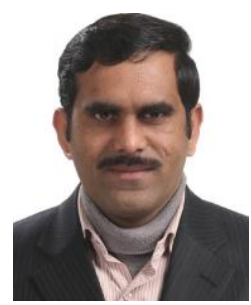

Dr. Janardhan Reddy Koduru is a Assistant Professor at Kwangwoon University, Seoul, Korea. His major is Environmental engineering, especially, physicochemical treatment of water containing toxic heavy metals and organic pollutants. He has also made significant contribution in the development of an advanced adsorbent and reactive materials for surface and ground water remediation. He has more than 50 publications in peerreviewed international journals and more than 40 reports in international and national conferences. 